\title{
Prophylactic antibiotics in patients with episiotomy following normal vaginal delivery: a randomised clinical trial
}

\author{
Nirav J. Garala ${ }^{1}$, Sabnam S. Nambiar ${ }^{2 *}$ \\ ${ }^{1}$ Department of Obstetrics and Gynecology, P. D. U. Medical College, Rajkot, Gujarat, India \\ ${ }^{2}$ Department of Obstetrics and Gynecology, Government Medical College, Kannur, Kerala, India
}

Received: 17 August 2019

Accepted: 28 August 2019

*Correspondence:

Dr. Sabnam S. Nambiar,

E-mail: sabblog1@gmail.com

Copyright: $\odot$ the author(s), publisher and licensee Medip Academy. This is an open-access article distributed under the terms of the Creative Commons Attribution Non-Commercial License, which permits unrestricted non-commercial use, distribution, and reproduction in any medium, provided the original work is properly cited.

\begin{abstract}
Background: Postpartum infectious complications following normal vaginal delivery remains a cause of major concern for the health care professionals due to higher morbidity and mortality and prolonged hospital stays and increased healthcare costs which makes us consider prophylactic use of antibiotics after normal vaginal delivery. On the other hand unjudicious use of antibiotics has led to widespread antibiotic resistance. Therefore, this study was carried out to validate the use of prophylactic antibiotics in these patients and their role in prevention of puerperial pyrexia, wound infections and prolonged hospital stay.

Methods: This Randomised clinical trial was conducted at KCHC-Kerala Co-operative Hospital Complex, Pariyaram, Kannur District, Kerala from $1^{\text {st }}$ March 2012 to $30^{\text {th }}$ April 2013. Eligible women were randomly assigned to group which does not receive prophylactic antibiotics (Group A) and group receiving prophylactic antibiotics (Group B). Patients in both the groups were examined every day till the patient was discharged from the hospital and observed for signs and symptoms of infected episiotomy wound, puerperial pyrexia and duration of hospital stay was noted.

Results: Mean age in years was 25.6 for Group A and 26.2 for Group B. Mean gestational age in both the groups was 37.6 weeks. Mean duration of labour was 6.62 and 6.22 hours for Group A and B respectively. 6 subjects in Group A and 5 subjects in Group B had puerperial pyrexia. 3 Subjects in Group A and 2 subjects in Group B had wound infection. The mean duration of hospital stay for Group A was 4.18 with SD of 1.0 while mean hospital stay for Group B was 4.01 with SD of 1.1.

Conclusions: By comparing subjects in both the groups with respect to puerperial pyrexia, wound infection and duration of hospital stay there was no statistical difference in any of the above criteria in both groups. Hence, in view of the risk of allergic reactions, toxicity and the selection of resistant strains the prophylactic administration of antibiotics does not seem to be justified in patients with episiotomy following vaginal delivery as per this study.
\end{abstract}

Keywords: Antibiotic prophylaxis, Duration of hospital stay, Episiotomy, Normal delivery, Puerperial pyrexia, Wound infection

\section{INTRODUCTION}

Pregnancy and child birth in itself is a natural phenomenon and majority of cases require no interference and only close observation, moral support and medical intervention when natural process fails or alters its path. Postpartum infectious complications following normal vaginal delivery remains a cause of major concern for the health care professionals due to higher morbidity and mortality and prolonged hospital stays and increased healthcare costs. 
With invention of penicillin and successive higher antibiotics, being widely and cheaply available; the use of antibiotics is more common in modern day obstetrics. On one hand, it has given us great control over the infections; on the other hand there is increase in antibiotic resistance and toxicity of the drugs due to non-judicious use of the antibiotics.

There is increase in methicillin resistant Staphylococcus aureus, vancomycin resistant Enterococcus, and extended- spectrum beta- lactamase- producing organisms. ${ }^{1-4}$ Both morbidity and mortality are increased in infections caused by these organisms, as they may be more virulent and are more difficult to treat because therapeutic options are limited. ${ }^{5,6}$ Antibiotic resistance development results mainly from the inappropriate use of antibiotics, incomplete courses of antibiotic therapies and the unnecessary use of broader spectrum regimens play a role. $^{7}$

Antibiotic prophylaxis is one of the methods used to reduce the risk of postpartum infections. ${ }^{8}$ Role of routine administration of prophylactic antibiotics to women after normal(uncomplicated) vaginal birth was studied and it was concluded that routine use of antibiotics did not reduce the incidence of urinary tract infections, wound infection or the length of maternal hospital stay. Antibiotics are not a substitute for infection prevention and control measures around the time of childbirth and the postpartum period. ${ }^{9}$ However question arises whether the statement is true even if there is episiotomy, $1^{\text {st }}$ or $2^{\text {nd }}$ degree perineal tear is present during delivery.

This study was conducted in patients of normal delivery with episiotomy, $1^{\text {st }}$ or $2^{\text {nd }}$ degree perineal tear to establish the role of prophylactic antibiotics in these patients in terms of incidence of puerperal pyrexia, wound infection and duration of hospital stay.

\section{METHODS}

This randomised clinical trial was conducted at $\mathrm{KCHC}$ Kerala Co-operative Hospital Complex, Pariyaram, Kannur District, Kerala from $1^{\text {st }}$ March 2012 to $30^{\text {th }}$ April 2013. All eligible women were explained about the study and the risks and benefits and written informed consent was obtained from the patients.

Eligible women were randomly assigned to group receiving prophylactic antibiotics and group which do not receive prophylactic antibiotics. Randomisation was done using a random number generating table.

The sample size was calculated based on our objective and our institutional data. We calculated that we would need 70 patients each arm to detect a $20 \%$ difference in rate of infection with alpha of 0.05 and power of $80 \%$, using two tailed tests.
Total numbers of patients in our study were 146 i.e. 73 in each group.

\section{Inclusion criteria}

- All patients who are in labour either spontaneous or induced

- Term or preterm or post-term, without any risk factors or complication,

- Who do not fit into the exclusion criteria and who are given episiotomy during delivery or perineal tears of grade 1 or 2 .

\section{Exclusion criteria}

- $\quad$ Patients with PROM, PPROM, patients with urinary tract infections, upper respiratory tract infections, lower respiratory tract infections, signs and symptoms of septicaemia or any other infection or the patients who have received oral or injectable antibiotic for any reason in past 2 weeks were excluded from the study.

- Patients with cardiac disease, overt diabetic, gestational diabetes mellitus, immunosuppressant drugs or disease causing immunosuppression

- Extension of episiotomy or perineal tears of grade 3 and 4

- Instrumental delivery like forceps or vacuum

- Prolonged labour

- Retained placenta and manual removal of placenta and post partum haemorrhage.

Patients were carefully selected after considering inclusion and exclusion criteria and study group was selected accordingly. The group was divided and randomised into two groups i.e. case and control group.

For the case group, no prophylactic antibiotic was given to the patient during the course of normal labour. Per Vaginal examination was done taking proper aseptic precaution. No antibiotics at the time of ARM. Antibiotics was given if there is prolonged labour or any other complication and excluded from the study.

For controls prophylactic antibiotics was given in the form of oral Cap Amoxicillin 500mg TDS after normal delivery with episiotomy for 5 days.

Episiotomy care was given to all the patients. The episiotomy care includes the vulva and buttocks are washed with soap and water down over the anus and sterile pad was applied. Patients in both the groups were examined every day till the patient was discharged from the hospital and signs and symptoms of infected episiotomy wound including redness or excessive swelling in the wound area, throbbing pain or tenderness in the wound area, red streaks in the skin around the wound or progressing away from the wound, pus or watery discharge collected beneath the skin or draining 
from the wound, generalized chills or fever were noted down.

Patients were discharged if wound healthy and baby fine and asked to review if any complaints at the site of episiotomy or any other complaints. All the patients were asked to come at the end of 6 weeks and history of puerperal period taken, complaints noted and patient were examined.

\section{RESULTS}

One hundred seventy subjects admitted to the Obstetrics and Gynecology Department of Pariyaram Medical College and Hospital were recruited for this study out of which twenty four subjects were excluded according to exclusion criteria (Figure 1). So a total of one hundred forty six subjects were included in this study from which 73 subjects each were allotted to Group A and Group B respectively. Where Group A consisted of study group with no antibiotic prophylaxis and Group B consisted of control group with antibiotic prophylaxis.

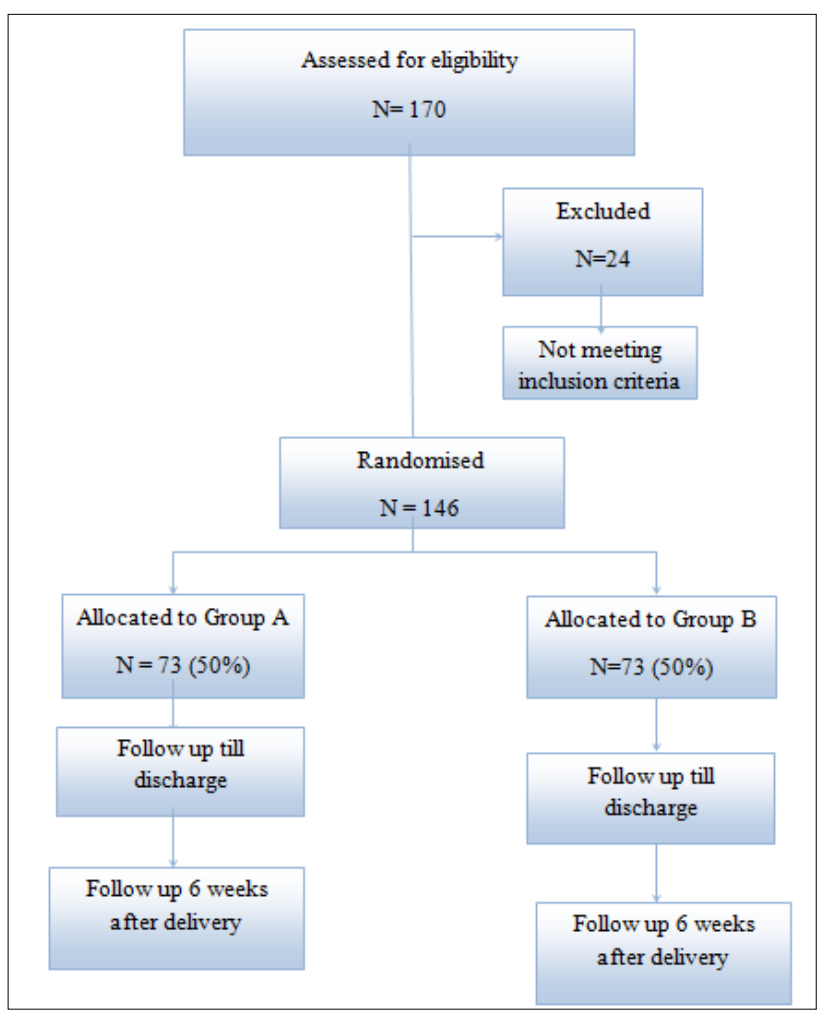

Figure 1: Sequence of events following admission of subjects.

Out of 146 patients, the age of the patient varies from 18 years to 39 years. In both the groups most of the patients were from 20-30 age group constituting of 60 (82\%) and $57(78 \%)$ patients in each Group A and B respectively. Patients in age group $>30$ years were 10 and 14 each in respective groups while patients with $<20$ years formed the smallest group with 3 and 2 patients in Group A and Group B respectively (Table 1 ).
The period of gestation for all the patients varied widely between 32 weeks 5 days to 39 weeks 6 days. Most of the patients in each group were term patients (37-40 weeks) with 59 patients in Group A and 61 patients in Group B which constituted $80.82 \%$ and $83.56 \%$ in respective groups (Table 1).

Table 1: Group characteristics.

\begin{tabular}{|lll|}
\hline Group characteristics & Group A & Group B \\
\hline $\begin{array}{l}\text { Age (in years) } \\
\text { Mean (SD) }\end{array}$ & $25.6(4.4)$ & $26.2(4.4)$ \\
\hline Parity 1/2/3 & $46 / 27 / 00$ & $44 / 27 / 02$ \\
\hline $\begin{array}{l}\text { Gestational age (in } \\
\text { weeks) Mean (SD) }\end{array}$ & $37.6(1.15)$ & $37.6(1.26)$ \\
\hline $\begin{array}{l}\text { Spontaneous/induced } \\
\text { delivery (S/I) }\end{array}$ & $20(\mathrm{~S}) / 53(\mathrm{I})$ & $24(\mathrm{~S}) / 49(\mathrm{I})$ \\
\hline $\begin{array}{l}\text { Duration of labour (in } \\
\text { hours) Mean }\end{array}$ & 6.62 & 6.22 \\
\hline $\begin{array}{l}\text { Mean duration of rupture } \\
\text { of membranes (in hours) }\end{array}$ & 4.25 & 3.93 \\
\hline
\end{tabular}

Out of total 146 patients, 90 patients (61.6\%) were primipara, 54 patients were $2^{\text {nd }}$ para and only 2 patients were $3^{\text {rd }}$ para. Group A with no antibiotic prophylaxis had 46 primi para and $272^{\text {nd }}$ para which formed $63 \%$ and $37 \%$ respectively in the group. While Group B with antibiotic prophylaxis had 44 primi para, $272^{\text {nd }}$ para and $23^{\text {rd }}$ para which constituted $60.2 \%, 37 \%$ and $2.7 \%$ respectively among the group (Table 1).

Table 2: Number of per vaginal examinations.

\begin{tabular}{|ll|l|}
\hline $\begin{array}{l}\text { Number of P/V } \\
\text { examination }\end{array}$ & Group A & Group B \\
\hline 1 & $05(6.84 \%)$ & $09(12.32 \%)$ \\
\hline 2 & $16(21.91 \%)$ & $14(19.17 \%)$ \\
\hline 3 & $29(39.72 \%)$ & $32(43.83 \%)$ \\
\hline 4 & $22(30.13 \%)$ & $14(19.17 \%)$ \\
\hline 5 & $01(1.36 \%)$ & $04(5.47 \%)$ \\
\hline
\end{tabular}

Out of 146 patients, 102 patients (69.9\%) were induced while $44(30.1 \%)$ patients went into labour spontaneously.

Duration of active phase of labour in all subjects varied from 4 hours to 11 hours. In Group A, 53.4\% patients (39) had duration of labour from 1-6 hours. While $46.6 \%$ (34) had labour $>6$ hours. In Group B, $64.4 \%$ patients (47) had duration of labour from 1-6 hours. While $35.61 \%$ (26) had labour $>6$ hours.

Mean duration of rupture of membranes is 4.25 hours in Group A and 3.93 hours in Group B. By comparing both the groups with t-test we get p-value of 0.248 which indicates that there is no significant difference in duration of rupture of membranes in each group and both groups are comparable. 
In most patients, 3 times per vaginal examination was done. The number of examination in each group is as per the Table 2. The difference in both groups was not statistically significant and both groups were comparable. (Table 2).

Table3: Distribution of subjects according to puerperial pyrexia.

\begin{tabular}{|llll|}
\hline $\begin{array}{l}\text { Puerperial } \\
\text { pyrexia }\end{array}$ & Group A & Group B & $\begin{array}{l}\text { Chi square test } \\
\text { p value }\end{array}$ \\
\hline Yes & 6 & 5 & \multirow{2}{*}{0.754} \\
\hline No & 67 & 68 & \\
\hline
\end{tabular}

According to Table 3, 6 subjects in Group A and 5 subjects in Group B had puerperial pyrexia. The difference between the two groups was not statistically significant with p-value of 0.754 , suggesting that prophylactic administration of antibiotics did not significantly reduce puerperial pyrexia.

Table 4: Distribution of subjects according to episiotomy infection.

\begin{tabular}{|llll|}
$\begin{array}{l}\text { Wound } \\
\text { infection }\end{array}$ & Group A & Group B & $\begin{array}{l}\text { Fisher's test } \\
\text { p value }\end{array}$ \\
\cline { 1 - 3 } Yes & 3 & 2 & \multirow{2}{*}{1.0000} \\
\hline No & 70 & 71 & \\
\hline
\end{tabular}

According to Table 4, 3 patients in Group A and 2 patients in group B had episiotomy wound infection. The difference in both the groups was not statistically significant with p-value of 1.0000. Suggesting that prophylactic administration of antibiotics was not associated with statistically significant reduction in wound infection rates.

Table 5: Duration of hospital admission in both groups.

\begin{tabular}{|lllll|}
\hline Duration of hospital stay & N & Mean & SD & p-value \\
\cline { 1 - 4 } Group A & 73 & 4.18 & 1.0 & \multirow{2}{*}{0.362} \\
\hline Group B & 73 & 4.01 & 1.1 & \\
\hline
\end{tabular}

Maximum number of patients was admitted for 4 days in both groups which is 36 for Group A and 49 for Group B. None of the patients was admitted for more than 9 days in any of the groups. Only 6 patients in Group A and 4 patients in Group B were admitted for more than 5 days suggesting lower rates of morbidity in both groups. The mean duration of hospital stay for Group A was 4.18 with SD of 1.0 while mean hospital stay for Group B was 4.01 with SD of 1.1 (Table 5).

By comparing both groups with t-test, we get p-value of 0.362 which shows that there is no statistical difference between both the groups and not using prophylactic antibiotic does not increase the duration of the hospital stay.

\section{DISCUSSION}

Emerging antibiotic resistance is a major global public health challenge. At the same time, untreated infections are one of the main causes of maternal mortality in low and middle-income countries. In India, institutional deliveries are being advocated to reduce the high burden of maternal mortality and morbidity. ${ }^{10}$ Increased access to basic and comprehensive emergency obstetric care through the practice of routine institutional deliveries can save the lives of many women, but increased use of antibiotics can also add to the progressing antibiotic resistance in India.

In this randomised study, role of prophylactic antibiotic in patients with episiotomy was studied and two groups, one containing patients who received prophylactic antibiotic and other group who did not receive any antibiotics were compared. It was found that there was no statistical difference between two groups in occurrence of peuperial pyrexia, episiotomy infection or duration of hospital stay. These findings are in agreement with findings of Janisch et al, Rechlin et al, and Heitmann et al, but not with study of Fernandez et al, Duggal et al. ${ }^{11-15}$

Our study consisted of total 146 cases and high risk patients like third and fourth degree perineal tear, forceps or vacuum deliveries, and manual removal of placenta were excluded from the study. While Janisch et al, studied 202 cases and included forceps, vacuum extraction, Breech delivery and MROP. ${ }^{11}$ Rechlin et al studied 838 cases which included forceps, vacuum extraction, MROP. ${ }^{12}$ Heitmann et al, studied 393 woman which included forceps delivery. ${ }^{13}$ Fernandez et al, studied 1291 woman. ${ }^{14}$

Our study group consisted of total 146 patients who were randomly distributed in two groups of 73 each. The mean age of patient in antibiotic group was 26.2 years and group without antibiotic was 25.6 years. Gestational age varied from 32 weeks 5 days to 39 weeks 6 days. Mean gestational age in each group was 37.6 with SD of 1.15 in Group A and 1.26 in Group B. In our study majority of the patients were primiparous. In Group A there were 46 $(63 \%)$ primi para and $27(37 \%) 2^{\text {nd }}$ para. In Group B there were $44(60.2 \%)$ primi para, $27(37 \%) 2^{\text {nd }}$ para. Out of 146 patients, 102 patients were induced and 44 went into labour spontaneously.

Heitman et al, conducted a trial comprising 393 women undergoing forceps or vacuum delivery from September 1986 to February 1989. It reported seven women with endomyometritis in the group given no antibiotic and none in prophylactic antibiotic group. This difference did not reach statistical significance, but the risk ratio reduction was 93\% (risk ratio0.07; 95\% confidence interval (CI) 0.00 to 1.21 ). There was no difference in the length of hospital stay between the two groups (mean difference 0.09 days; $95 \%$ CI -0.23 to 0.41 ).In our study the mean duration of hospital stay for Group A was 4.18 
with SD of 1.0 while mean hospital stay for Group B was 4.01 with SD of 1.1.

There is no statistical difference between both the groups and not using prophylactic antibiotic does not increase the duration of the hospital stay which is consistent with the results of Heitman et al. But the incidence of postpartum endometritis was not included in our study. Another difference is that operative vaginal deliveries were not included in our study while Heitman et al, included women with operative vaginal delivery only.

In study of Duggal et al, 147 women who had thirddegree or fourth-degree perineal tears after vaginal delivery were randomized to receive a single intravenous dose of a second-generation cephalosporin (cefoxitin) or placebo before repair of third-degree or fourth-degree perineal tears. Of these, 83 patients received placebo and 64 patients received antibiotics. Forty patients (27.2\%) did not return for their 2-week appointment. Of the patients seen at 2 weeks postpartum, 4 of $49(8.2 \%)$ patients who received antibiotics and 14 of $58(24.1 \%)$ patients who received placebo developed a perineal wound complication $(\mathrm{P}=0.037)$. There were no differences between groups in parity, incidence of diabetes, operative delivery, or third-degree compared with fourth-degree lacerations. By 2 weeks postpartum, patients who received prophylactic antibiotics at the time of third- or fourth-degree laceration repair had a lower rate of perineal wound complications than patients who received placebo.

The results of this study are inconsistent with results of our study. In our study 3 patients in Group A and 2 patients in Group B had wound infection. The difference in both the groups was not statistically significant with pvalue of 1.0000. Suggesting that prophylactic administration of antibiotics was not associated with statistically significant reduction in wound infection rates. But the subjects included in the study of Duggal et al, had third or fourth degree perineal tears while subjects in our study had an episiotomy or first or second degree perineal tear. Exclusion of patients with third and fourth degree perineal tear from our study might be the reason for the difference in the observation.

202 cases of vaginal obstetric procedures (forceps and vacuum extraction, breech delivery and manual removal) were reviewed by Janisch et al, with regard to assessing the value of prophylactic administration of antibiotics. Criteria for the evaluation were fever post partum, duration of stay in hospital and involution of the uterus. The results showed that the prophylactic administration of antibiotics had no significant effect on these parameters, with or without the simultaneous administration of oxytocics. Hence, in view of the risk of allergic reactions, toxicity and the selection of resistant strains the prophylactic administration of antibiotics does not seem to be justified in vaginal obstetric procedures as per the study. This study has results consistent with our study but case selection is different as subjects with operative vaginal delivery and manual removal of placenta are not included in our study.

The limitations of this study were, very limited data is available to compare this study as studies regarding prophylactic use of antibiotics specifically in episiotomy or $1^{\text {st }}$ or $2^{\text {nd }}$ degree perineal tear have not been carried out in past. So it cannot be commented whether the results of this study are comparable with previous studies or not. The antibiotic given was Amoxicillin so that the effects of other antibiotics cannot be ascertained. Neonatal outcome was not considered in this study whether there were any differences in neonatal complications as septicemia.

\section{CONCLUSION}

Prophylactic antibiotics are not recommended for patients with episiotomy in absence of other risk factors. Prophylactic antibiotics are not recommended for patients with $1^{\text {st }}$ and $2^{\text {nd }}$ degree perineal tear. Routine use of prophylactic antibiotics should be discouraged. Routine prophylactic antibiotics are not effective in preventing peuperial pyrexia, wound infection and prolonged hospital stay.

\section{ACKNOWLEDGMENTS}

Authors would like to thank Dr P. V. Jose (Head of Unit), Dr Ajith and Dr T. N. Rajalakshmi (Head of Department) who were a constant source of inspiration and motivation and for their constant support. Authors would also like to thank Dr Usha for her help analysing the data.

\section{Funding: No funding sources \\ Conflict of interest: None declared \\ Ethical approval: The study was approved by the Institutional Ethics Committee}

\section{REFERENCES}

1. Shopsin B, Mathema B, Martinez J, Ha E, Campo ML, Fierman A, et al. Prevalence of methicillinresistant and methicillin-susceptible staphylococcus aureus in the community, $J$ Infect Dis. 2000;182(1):359-62.

2. Boyce J. Increasing prevalence of methicillinresistant staphylococcus aureus in the United States. Infect Control Hospital Epidemiol. 1990;11(12):63942.

3. Pan ES, Diep BA, Carleton HA, Charlebois ED, Sensabaugh GF, Haller BL, et al. Increasing prevalence of methicillin-resistant staphylococcus aureus infection in California Jails. Clin Infect Dis. 2003;37(10):1384-8.

4. Pugliese G. Increase in vancomycin-resistant enterococci. Infect Control Hospital Epidemiol. 1995;16(9):505-5. 
5. Griffiths C, Lamagni TL, Crowcrof NS. Trends in MRSA in England and Wales: analysis of morbidity and mortality data for 1993-2002, Health statistics: 2004.

6. Shorr A, Shorr AF, Tabak YP, Gupta V, Johannes RS, Liu LZ, et al. Morbidity and cost burden of methicillin-resistant Staphylococcus aureus in early onset ventilator-associated pneumonia. Critical Care. 2006;10(3):R97.

7. Levy, Stuart B. "The challenge of antibiotic resistance." Scientific American. 1998;278(3):46-53.

8. Thinkhamrop J, Hofmeyr GJ, Adetoro O. Prophylactic antibiotic administration in pregnancy to prevent infectious morbidity and mortality. In: The Cochrane Library; 2002;4.

9. Hugonnet S, Pittet D. Hand hygiene revisited: lessons from the past and present. Curr Infect Dis Rep. 2000;2:484-9.

10. Kumar S. Reducing maternal mortality in India: policy, equity, and quality issues. Indian $\mathrm{J}$ Public Health. 2010;54:57-64.

11. Janisch H, Philipp K, Riss P. The effect of antibiotic prophylaxis in vaginal obstetric procedures. Wiener KlinischWochenschrift.1979;91:227-30.

12. Rechlin VD, Wolf M, Koeniger W. Value of the preventive use of antibiotics following vaginal obstetric operations. Zentralblatt Fur Gynakologie. 1988;110:570-4.

13. Heitmann JA, Benrubi GI. Efficacy of prophylactic antibiotics for the prevention of endomyometritis after forceps delivery. Southern Med J. 1989;82:9602.

14. Fernandez H, Gagnepain A, Bourget P, Peray P, Frydman R, Papiernik E, et al. Antibiotic prophylaxis against postpartum endometritis after vaginal delivery: a prospective randomized comparison between Amox-CA Augmentin) and abstention. Eu J Obstet Gynecol Repro Biol. 1993;50:169-75.

15. Duggal N, Mercado C, Daniels K, Bujor A, Caughey AB, El-Sayed YY. Antibiotic prophylaxis for prevention of postpartum perineal wound complications: a randomized controlled trial. Obstet Gynecol. 2008;111(6):1268-73.

Cite this article as: Garala NJ, Nambiar SS.

Prophylactic antibiotics in patients with episiotomy following normal vaginal delivery: a randomised clinical trial. Int J Reprod Contracept Obstet Gynecol 2019;8:3846-51. 